\title{
Forensic Excavation of Rock Masses: A Technique to Investigate Discontinuity Persistence
}

\author{
J. Shang ${ }^{1,4}{ }_{(1)}$ S. R. Hencher ${ }^{1,2,3} \cdot$ L. J. West ${ }^{1} \cdot$ K. Handley ${ }^{1}$
}

Received: 3 April 2017 / Accepted: 25 July 2017/Published online: 8 August 2017

(c) The Author(s) 2017. This article is an open access publication

\begin{abstract}
True persistence of rock discontinuities (areas with insignificant tensile strength) is an important factor controlling the engineering behaviour of fractured rock masses, but is extremely difficult to quantify using current geological survey methodologies, even where there is good rock exposure. Trace length as measured in the field or using remote measurement devices is actually only broadly indicative of persistence for rock engineering practice and numerical modelling. Visible traces of discontinuities are treated as if they were open fractures within rock mass classifications, despite many such traces being non-persistent and actually retaining considerable strength. The common assumption of $100 \%$ persistence, based on trace length, is generally extremely conservative in terms of strength and stiffness, but not always so and may lead to a wrong prediction of failure mechanism or of excavatability. Assuming full persistence would give hopelessly incorrect predictions of hydraulic conductivity. A new technique termed forensic excavation of rock masses is introduced, as a procedure for directly investigating discontinuity persistence. This technique involves non-explosive excavation of rock masses by
\end{abstract}

J. Shang

shangjunlongcsu@gmail.com

$\bowtie$ S. R. Hencher

stevehencher@btinternet.com

1 Engineering Geology and Hydrogeology Group, School of Earth and Environment, University of Leeds, Leeds, UK

2 Department of Earth Sciences, University of Hong Kong, Hong Kong SAR, China

3 Hencher Associates Limited, Ilkley, UK

4 Nanyang Centre for Underground Space, School of Civil and Environmental Engineering, Nanyang Technological University, Singapore, Singapore injecting an expansive chemical splitter along incipient discontinuities. On expansion, the splitter causes the incipient traces to open as true joints. Experiments are described in which near-planar rock discontinuities, through siltstone and sandstone, were opened up by injecting the splitter into holes drilled along the lines of visible traces of the discontinuities in the laboratory and in the field. Once exposed the surfaces were examined to investigate the pre-existing persistence characteristics of the incipient discontinuities. One conclusion from this study is that visible trace length of a discontinuity can be a poor indicator of true persistence (defined for a fracture area with negligible tensile strength). An observation from this series of experiments was that freshly failed surfaces through pre-existing rock bridges were relatively rough compared to sections of pre-existing weaker areas of geologically developed (though still incipient) discontinuities. Fractographic features such as hackle and rib marks were typical of the freshly broken rock bridges, whereas opened-up areas of incipient discontinuity were smoother. Schmidt hammer rebound values were generally higher for the rock bridge areas, probably reflecting their lower degree of chemical and physical weathering.

Keywords Discontinuity persistence $\cdot$ Forensic excavation - FERM - Rock mass - Incipient rock discontinuity $\cdot$ Rock bridges $\cdot$ Tensile strength $\cdot$ Rock fracture networks

\section{Introduction}

Persistence is defined as the areal extent of a rock discontinuity (ISRM 1978). Its implications for the strength of rock masses and their stability in rock engineering are obvious (e.g. Kemeny 2005), but this property is extremely 
difficult to determine in practice (e.g. O'Reilly 1980; Einstein and Baecher 1983; Park 2005; Kim et al. 2007; Wasantha et al. 2011; Bonilla-Sierra et al. 2015; Tucky and Stead 2016). The persistence and aperture of discontinuities also influence their hydraulic properties and flow pathways (Fu et al. 2016; Medici et al. 2016). Figure 1a illustrates the usual, and rather simplistic, definition of areal persistence $K_{\mathrm{A}}$ which is expressed by:

$K_{\mathrm{A}}=\sum\left[\left(A_{\mathrm{D}}-A_{\mathrm{Bi}}\right) / A_{\mathrm{D}}\right]$

in which $A_{\mathrm{D}}$ is the gross area of a joint plane, including the area of intact rock bridges $\sum A_{\mathrm{Bi}}$, and the fully persistent areas (Einstein et al. 1983).

In reality, often only a small area of discontinuity is fully open and lacks significant tensile strength; much of the area represented by a visible discontinuity in exposures is incipient and maintains considerable shear and tensile strength; the third section, that maintains the geometry of the discontinuity, but without visible trace, comprises true 'rock bridges' in the sense of intact rock with no incipient geological weakness (Hencher 2014, 2015). An example of an intact rock bridge, exposed following a direct shear test, is provided in Fig. 2. The bridge comprises only slightly decomposed crystal tuff, with some iron staining associated with biotite. Away from the rock bridge the joint is thickly coated with secondary iron oxides and there are contours of varying discolouration surrounding the rock bridge itself (Fig. 2b). The true cohesion measured from shearing the rock bridge was about $0.75 \mathrm{MPa}$ (pro rata for the rock bridge area) which, although significant, is small compared to what one might expect for intact slightly decomposed crystal tuff (in excess of $10 \mathrm{MPa}$ ). This indicates that the 'bridge' itself had some pre-existing (micro-fracturing) damage associated with original geological discontinuity propagation; it is evident that the 'proto-joint' has then been gradually weathered and weakened (Hencher 2006), towards the condition where it would eventually become a true, through-going 'joint', lacking significant tensile strength as defined by ISRM (1978).

The visible trace length of discontinuities is often taken as representative of actual persistence (ISRM 1978; Priest and Hudson 1981; Einstein et al. 1983; Park 2005; Palmstrőm 2005; Kim et al. 2007; Umili et al. 2013; Han et al.
2015; Jiang et al. 2015) although such practice is questionable (Pells et al. 2017).

Einstein et al. (1983) defined linear persistence $K_{\mathrm{L}}$ as:

$K_{\mathrm{L}}=\sum\left[J_{\mathrm{i}} /\left(J_{\mathrm{i}}+B_{\mathrm{i}}\right)\right]$

in which $\sum B_{\mathrm{i}}$ is the sum of rock bridge length and $\sum J_{\mathrm{i}}$ is the sum of joint trace length (see Fig. 1b).

In numerical modelling, the contribution of the tensile strength of discontinuities or intact rock bridges to overall rock mass strength can be estimated using 'damage models' (e.g. Alzo'ubi et al. 2007), but this approach is largely a matter of judgement perhaps linked to empirical observation of rock mass movement (essentially a process of trial and error).

The truth is that, owing to its three-dimensional nature and limitations of measurement, hidden within the rock mass, very little is known about true discontinuity persistence, and there have been few studies of this parameter. Importantly, Rawnsley (1990) during his research concluded that 'persistence' (in the sense of visible traces in exposures) could not be extrapolated into rock masses on the basis of consideration of geological factors although these current authors still suspect that this may well be a fruitful line for research for the future, following the application of FERM as advocated here. In the same way, persistence cannot be reliably quantified through other observations such as surface laser scanning (Abellan et al. 2006) or digital imaging (Harrison and Reid 2010). Park (2005) similarly concluded that it is impossible in practice to measure discontinuity area based on field investigation. Other researchers have attempted to quantify this parameter better, but all are restricted to making judgements based on the limitations of rock exposure (e.g. Sturzenegger and Stead 2009; Ferrero et al. 2009; Tuckey and Stead 2016). Hencher $(2014,2015)$ noted that true persistence depends on a range of factors including geological origin, stress history and degree of weathering. He suggested that, as a first pass, incipient discontinuities as observed in core or exposures should be classified (broadly judged) as 'weak', 'moderately strong' or 'strong' relative to the tensile strength of the parent rock, and this approach is supported by recent experimental studies (Shang et al. 2015, 2016).
Fig. 1 Definitions of rock discontinuity persistence. a Areal extent of a discontinuity plane (true persistence) and b linear extent definition (linear persistence); for more details see text. Adapted from Einstein et al. (1983) (a)

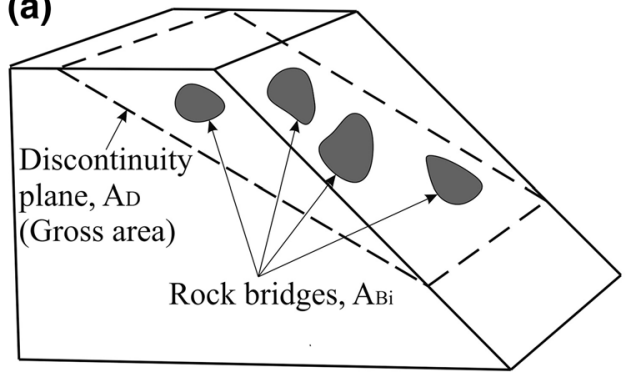

(b)

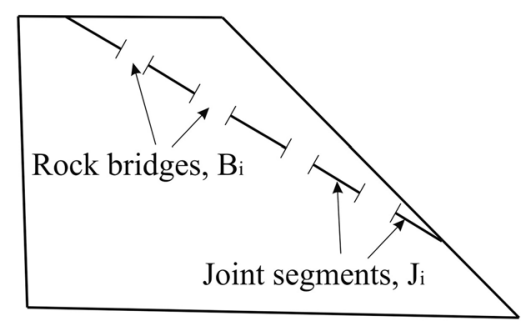


Fig. 2 Example of a rock bridge, observed following direct shear test on section of 'intact' core. a General view of tested area of joint (cm scale). Most is red-brown and coated with iron oxides. b Close-up of part of rock bridge-grey with minor signs of chemical decomposition. Boundary between bridge area and coated section is marked in some areas with lines of discolouration derived from the chemical decomposition process as the bridge is gradually eaten away (colour figure online) (a)

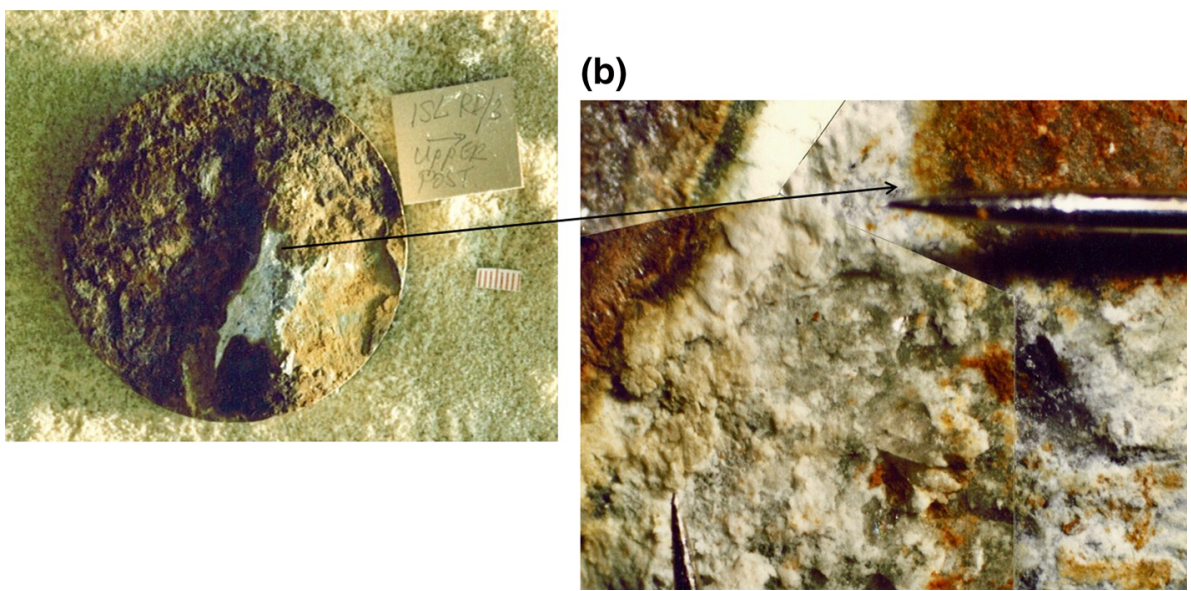

\section{Methodology: Forensic Excavation of Rock Masses}

In this paper, a new technique, FERM, is introduced as a method for investigating directly the extent of incipient rock discontinuities in the laboratory and field. It is envisaged that the technique might be employed as a way to address ongoing problems in characterising rock masses.

The method involves non-explosive splitting along a planar or near-planar incipient rock discontinuity. The three-dimensional nature of the discontinuity can then be examined allowing measurement of pre-existing areal extent (persistence) and the nature of rock bridges.

\subsection{Chemical Splitter and Operation Principle}

A commercially available chemical splitter 'Dexpan', comprising $\mathrm{SiO}_{2}, \mathrm{Al}_{2} \mathrm{O}_{3}, \mathrm{Fe}_{2} \mathrm{O}_{3}, \mathrm{CaO}, \mathrm{MgO}$ and $\mathrm{SO}_{3}$ (Gani 1997; Huynh and Laefer 2009), was used for breaking the rock in this study. On mixing with water the grout expands considerably over a period of hours. Chemical splitters have been employed extensively in rock engineering projects where blasting is not allowed (Natanzi and Laefer 2014). However, for engineering works current usage is for cutting to a pre-defined geometry as illustrated in Fig. 3 rather than as a means of opening up individual discontinuities.

\subsection{Experimental Procedure of FERM}

Figure 4 illustrates the FERM testing procedure:

- Stage 1-Holes with diameter of $27 \mathrm{~mm}$ were drilled to follow the apparent planes of incipient discontinuities using a battery-powered drill and spacing of around $200 \mathrm{~mm}$. Holes were terminated within the test blocks to prevent leakage of the chemical splitter.

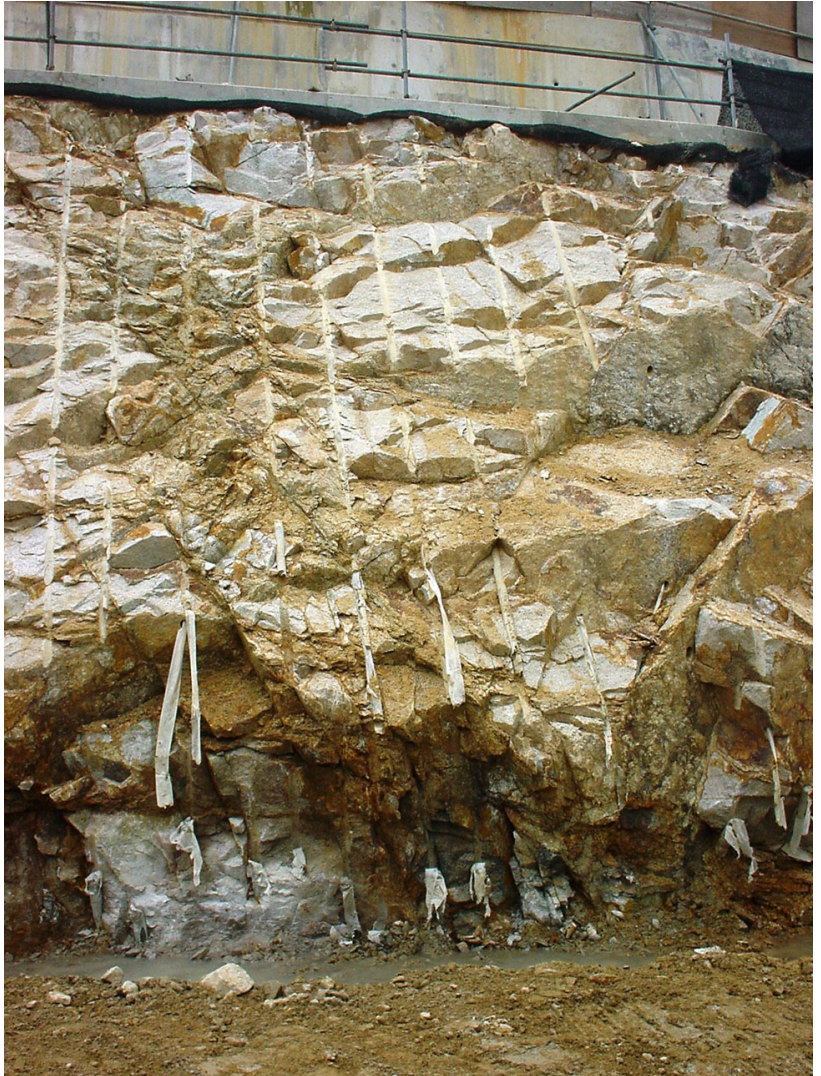

Fig. 3 Expansive chemical grout employed in pre-drilled holes to form rock cut slope. Castle Peak Road formation works, Hong Kong

- $\quad$ Stage 2-The expansive powder and water were mixed to the recommended ratio $(3.3 \mathrm{~kg} / \mathrm{L})$.

- Stage 3-Holes were filled with the chemical splitter. A plastic cover was placed over the holes.

- Stage 4-The chemical splitter hardens gradually and expands to open up the incipient discontinuity, typically over $24 \mathrm{~h}$. Secondary tools (an excavator, forklift, wedges and chisels) were used as necessary to complete 


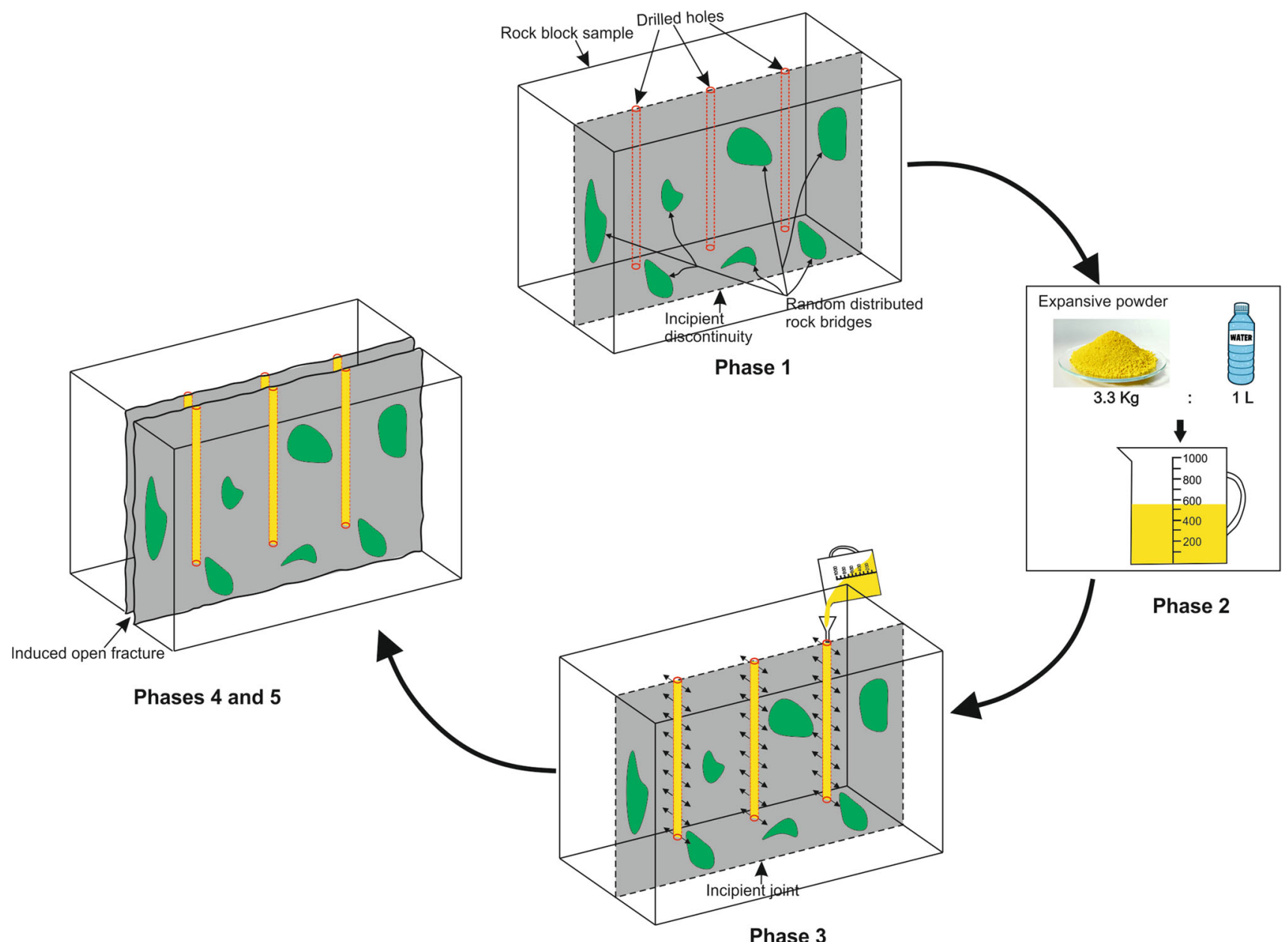

Fig. 4 Schematic diagram of the testing procedure for FERM. Figure not to scale

the opening up of the incipient fractures initiated by the expansive grout.

- Stage 5-Joint surface examination and description.

\section{Geology of Study Sites}

Figure 5 shows the locations and geology of Dry Rigg Quarry (DRQ) and Blackhill Quarry (BQ), located in the Horton Formation (Devonian) and the Midgley Grit Formation (Carboniferous), respectively, in Yorkshire, UK.

The quarried rock at DRQ is typically medium to dark grey, strong to extremely strong siltstone. Geological structures include wonderful examples of folding and faulting; the main pervasive discontinuities include mineral veins, bedding planes and joints, and these can be seen throughout the quarry faces, varying in extent and apparent spacing with degree of weathering and stress relief (see Fig. 6a, b and refer to Hencher 2015). The tensile strength of the calcite mineral veins through this rock, at the laboratory scale, has been reported by Shang et al. (2016).

The rock at $\mathrm{BQ}$ comprises a sequence of 20 and 30 metres of predominantly well-cemented sandstone and gritstone (Fig. 6c, d). The rock is typically red-brown and yellow because of the presence of iron oxides that occur as pore linings and pore fillings and replace ferromagnesian grains such as biotite (Smedley et al. 2005).

\section{FERM Experiment of Midgley Grit Sandstone at Laboratory Scale}

\subsection{Block Sample Description}

A large block sample of Midgley Grit Sandstone was collected from BQ, as shown in Fig. 7a. The block contained six visible traces of discontinuities, labelled (1)-(6). Incipient joint traces (1), (2) and (3) intersected one another (see Fig. 7a, top view). Incipient bedding (dashed lines in 


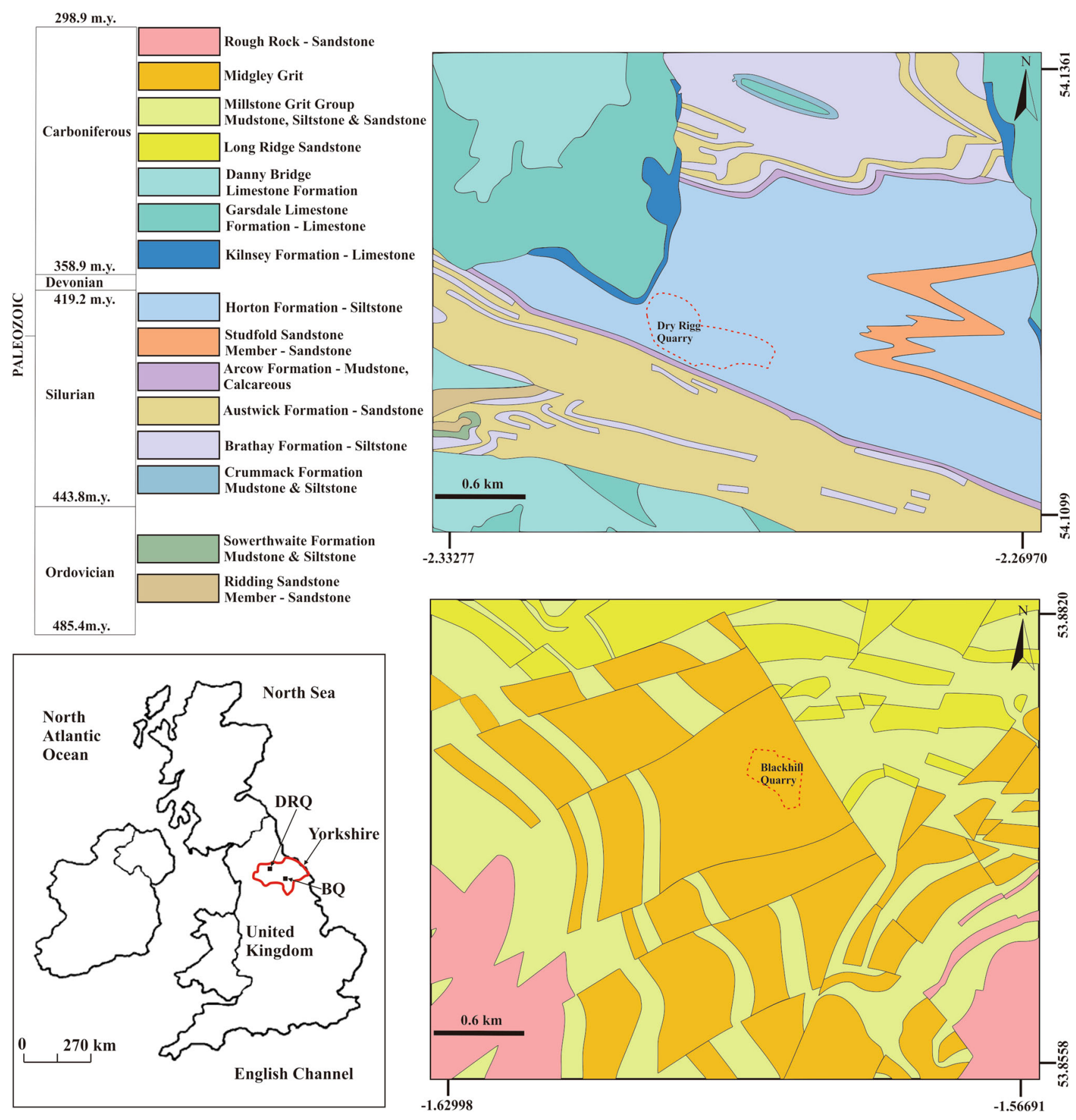

Fig. 5 Simplified geological maps and locations of Blackhill Quarry and Dry Rigg Quarry in Yorkshire, UK. Data from the British Geological Survey website (http://www.bgs.ac.uk/). (Please refer to the web version of this article for colour interpretation.)

Fig. 7a, left and front views) is also present. Relative orientations of these discontinuity traces including exposed surfaces are plotted in Fig. 7b assuming a north reference direction as shown in the top view. Incipient joint (1) appears as a trace on all free surfaces (see Fig. 7a, top and rear views), whereas other joints appeared to be less well developed in surface expression.

\subsection{FERM Experiment Procedure and Sample Failure Pattern}

Figure 8 illustrates the FERM testing procedure in the laboratory. Holes with diameter of $27 \mathrm{~mm}$ were drilled along incipient joint traces (1), (2) and (3) to a depth of around $150 \mathrm{~mm}$, and chemical splitter injected (Fig. 8a, b). 

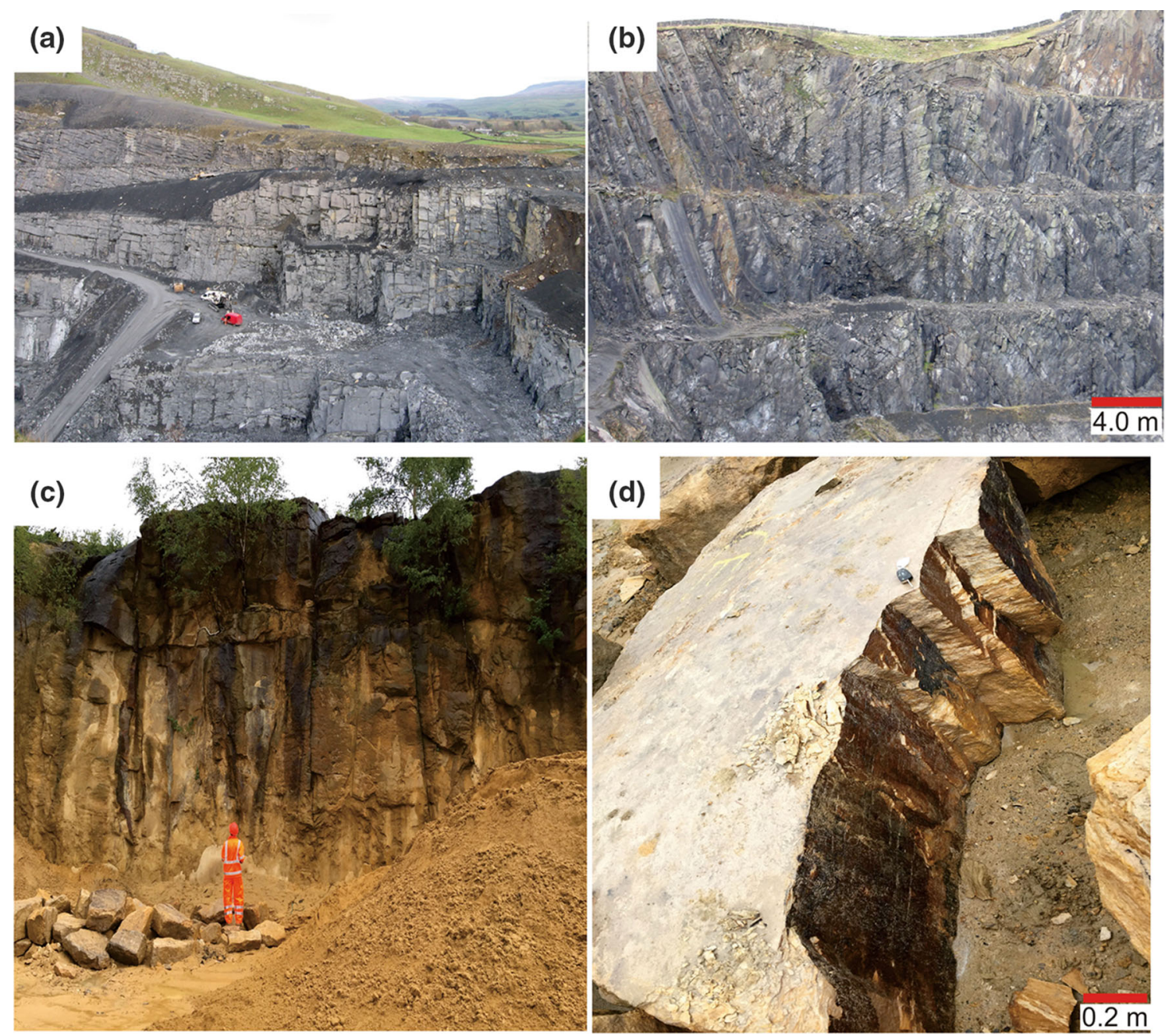

Fig. 6 Example exposures from Dry Rigg Quarry (DRQ), North Yorkshire, and Blackhill Quarry (BQ), West Yorkshire, UK

Figure $8 \mathrm{c}$ and $\mathrm{d}$ shows the failure patterns after $24 \mathrm{~h}$. As anticipated, the block sample split following pre-existing discontinuity traces. Two incipient horizontal bedding planes were also opened up (Fig. 8d). One incipient rock joint (3) changed from near-vertical to inclined below one of the opened bedding planes (Fig. 8d). Incipient joint (4) also opened up during this test although it was not targeted in the experiment.

\subsection{Laboratory Experiment Results and Discussion}

The split rock block pieces are shown in Fig. 9. From the revealed joint planes, it was observed that all incipient joints terminated at bedding planes (indicated by red lines).

Generally, the persistent joint segments (outlined by white dashed lines) exhibited various degrees of weathering in a similar manner to the samples described by Shang et al. (2016). The stained segments were identified, and their areal extent measured approximately using AutoCAD. Pre-existing areal persistence values of incipient rock joints
(1), (2), (3) and (4) were calculated as $85,37,32$ and $90 \%$, respectively, according to the areal extent definition in Fig. 1a. The persistence was quantified under the assumption that persistent areas were stained. This assumption may not be true for some newly generated fractures for which surfaces are still in fresh state, but for many cases, especially those situations exposed in the field (like the tested sample), the discoloration of minerals on persistent discontinuity areas is evidence for the identification of persistent areas.

Importantly, with respect to general characterisation and judgments that are made routinely in rock engineering, there was no indication of these likely areal extents based on examination of the extent of exposed incipient joint traces prior to the FERM testing; nor was there any obvious relationship between exposed traces and rock bridge areas post-testing. Examination of scattered weathering areas on incipient joint plane (3) provides some clues that weathering might be expected to be the main factor affecting joint incipiency. 
(a)
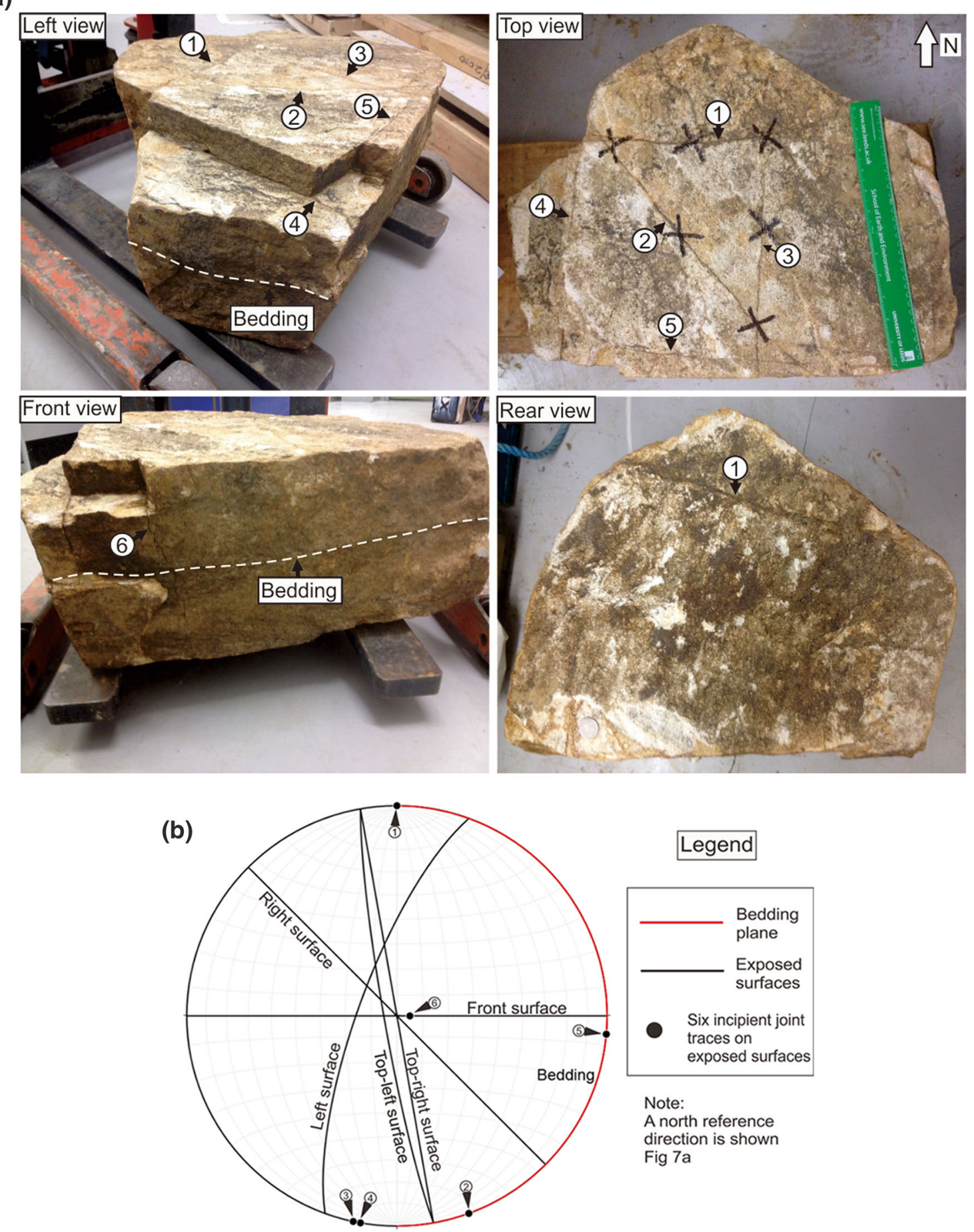

Fig. 7 a View of block of Midgley Grit Sandstone tested in the laboratory, with incipient bedding discontinuities and six visible joint traces. The rule for scale is $314 \mathrm{~mm}$. b Stereographic representative of six incipient joint traces and exposed surfaces shown in $\mathbf{a}$. Bedding (red line in b) is assumed as horizontal. Note that discontinuity surfaces are plotted as planes and traces are plotted as poles (colour figure online) 

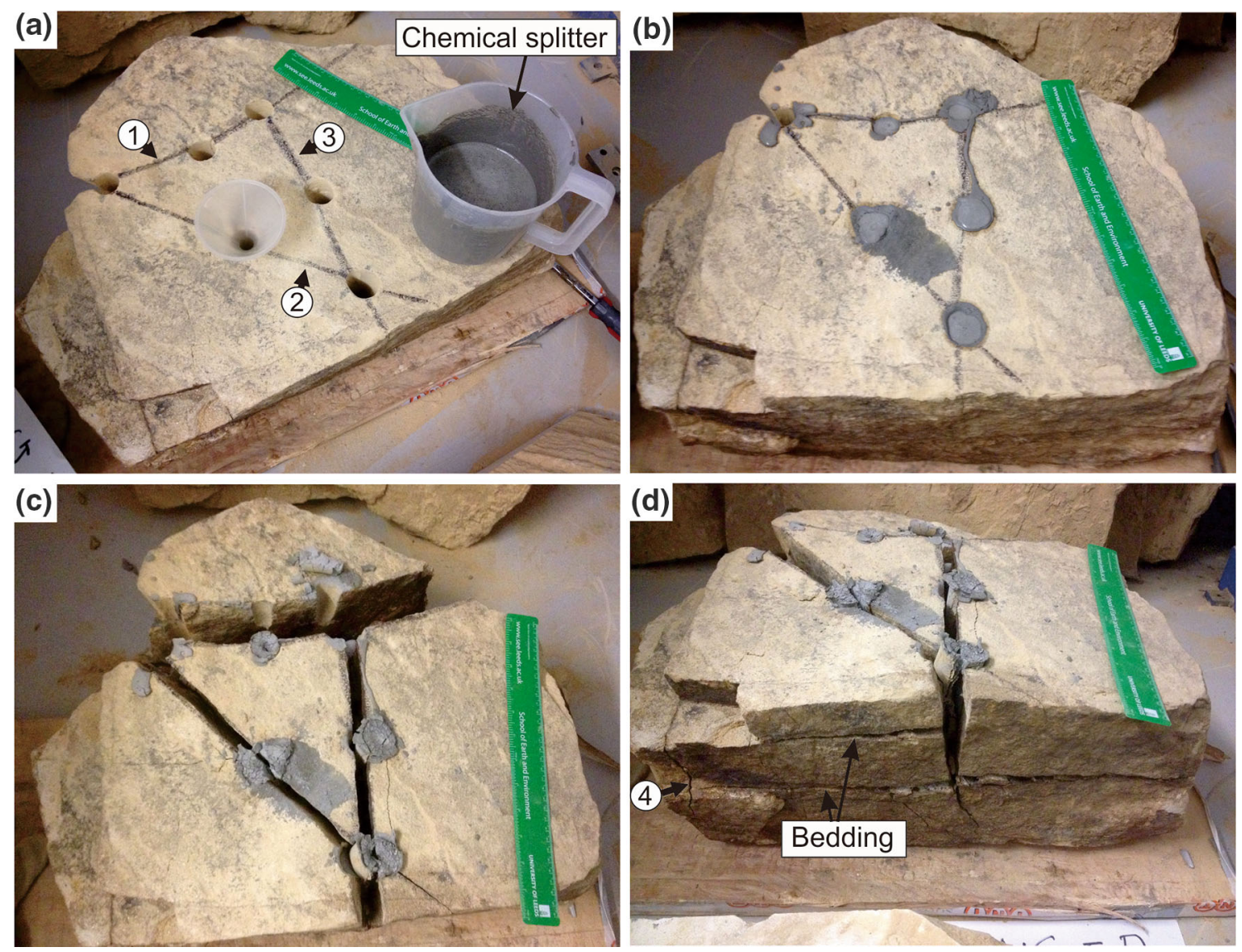

Fig. 8 FERM testing procedure along incipient rock discontinuities (1), (2) and (3) of Midgley Grit Sandstone block shown in Fig. 7a. a Six holes with a diameter of $27 \mathrm{~mm}$ were drilled along these incipient joints to a depth of $150 \mathrm{~mm}$. b The chemical splitter was injected into

the pre-drilled holes. c Induced fractures along pre-existing incipient joint traces after $24 \mathrm{~h}$. Two horizontal parallel fractures were induced along bedding planes as shown in $\mathbf{d}$. The rule for scale is $314 \mathrm{~mm}$

\section{A Larger-Scale FERM Experiment Using Midgley Grit Sandstone}

Two large blocks of Midgley Grit Sandstone (Block 1 and Block 2) with through-going traces of incipient rock joints were identified for FERM testing in the field (Figs. 10, 11).

\subsection{Larger-Scale FERM Experimental Procedure}

Figures 10 and 11 illustrate the field-scale testing procedure and the failure patterns that were created after $24 \mathrm{~h}$. For Block 1, holes were drilled with a separation of $200 \mathrm{~mm}$ along the joint trace on the top surface (Fig. 10a). All holes were drilled to a depth of approximately $280 \mathrm{~mm}$, i.e. more than $50 \%$ of the block depth. Figure $11 \mathrm{~b}$ shows Block 2 with a single vertical incipient joint. The linear extent of the joint trace on the top surface is $56 \%$. Seven holes with diameter of $27 \mathrm{~mm}$ were drilled along the incipient joint plane.

\subsection{Results of Larger-Scale FERM Experiments on Midgley Grit Sandstone}

Figure 12 shows opened joint surfaces and joint roughness profiles of incipient joint from Block 1. Two fresh scratches (Fig. 12a) produced during splitting provided a reference for identifying colour variation. Fresh rock bridge (RB) areas with feather markings are indicated by the dashed lines (see Figs. 12a, b). The pre-existing persistent (albeit still incipient) joint area (left part of Fig. 12a; right part of 12b) was variably stained and lacked feather markings.

Roughness profiles were measured using a profile meter. In Fig. $12 \mathrm{a}_{1}$, joint profiles 1-2 were planar, profiles 3-4 were undulating, and profiles 5-8 were stepped (following definitions of ISRM 1978; Barton and Choubey 1977; Norbury 2010). It can be seen that the pre-existing persistent joint area was relatively flat, while the rock bridge area was more variable and rough with high asperities. The areal persistence of joint surface B was about $48 \%$ 


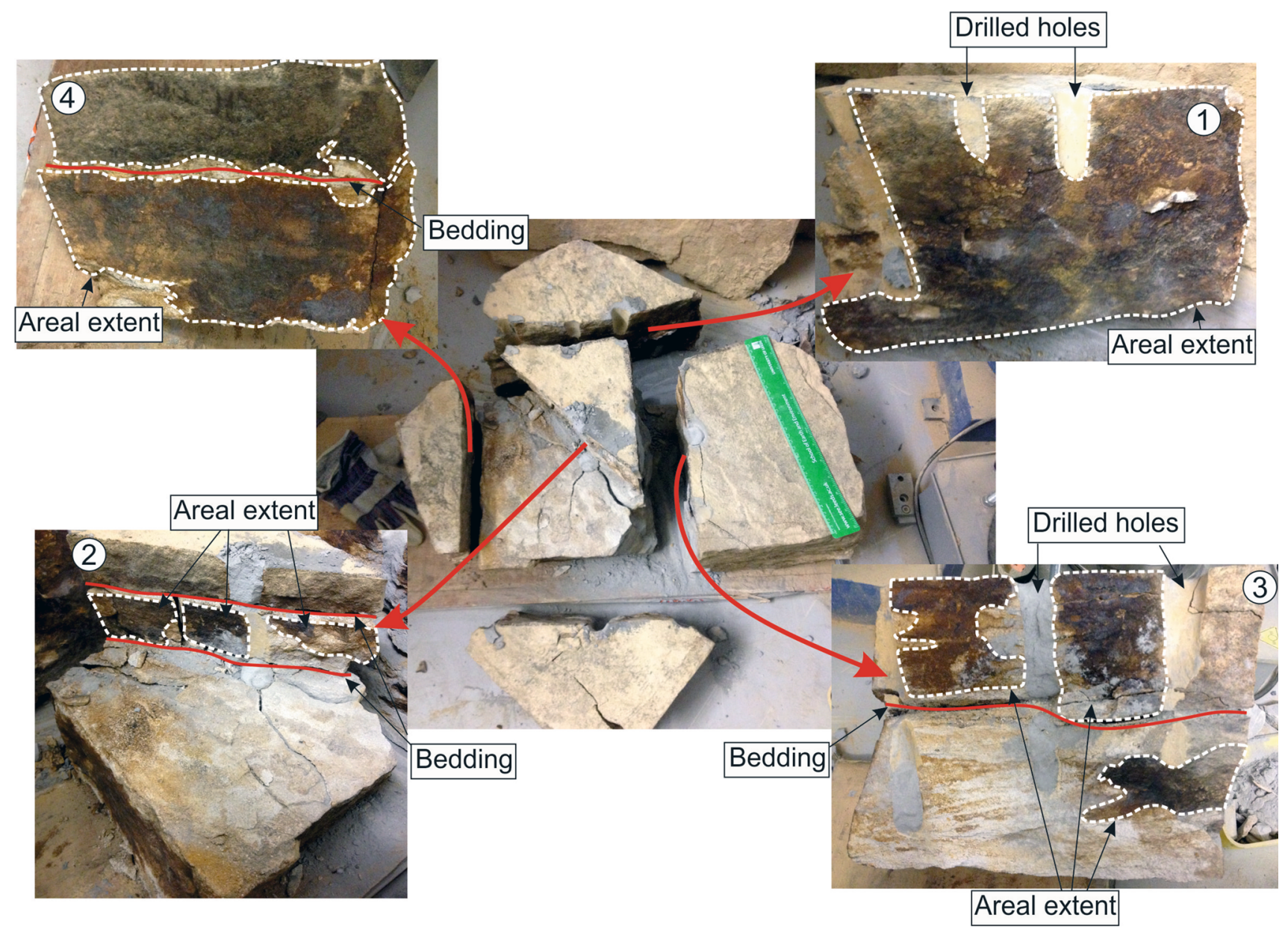

Fig. 9 Incipient joint surfaces exposed after testing of Midgley Grit Sandstone block shown in Fig. 7a. Red lines correspond to an opened bedding plane. The rule for scale is $314 \mathrm{~mm}$ (colour figure online)

compared to the linear persistence from joint trace of approximately $55 \%$.

Figure 13a and $\mathrm{b}$ shows the opened incipient joint surfaces and roughness profiles of Block 2. The persistent area was stained heavily to black at the bottom, and it varied gradually to reddish brown and grey towards the top of the block, which may reflect progressive development of the discontinuity with time from an incipient to open state (see further discussion in Hencher and Knipe 2007).

As for Block 1, feather markings were observed in the relatively fresh rock bridge areas, but not in the pre-existing persistent (albeit incipient) areas. Stained feather markings were observed at the transition zones between the persistent joint area and rock bridge area. The areal extent of this persistent area of the incipient joint was 31\% compared to the observed linear persistence from trace length of $56 \%$. The roughness profiles of Block 2 were planar (1) and (2) in the persistent area, undulating (3) and
(4) in transition zone, and stepped (5)-(10) in the rock bridge area.

Schmidt hammer (SH) tests (L-type) were performed on the four exposed joint walls, shown in Figs. 12a, b, $13 \mathrm{a}$ and $\mathrm{b}$, respectively, according to the ISRM standard (Aydin 2014). Red and green dots on exposed surfaces correspond to the $\mathrm{SH}$ testing points on persistent joint area and rock bridges, respectively. Joint walls were cleaned to eliminate effects from loose debris prior to $\mathrm{SH}$ testing. Each point was tested twice perpendicular to the surface.

Figure 14a shows hardness rebound values against the distance along Midgley Grit Block 1, measured from the left edge of the Block. For the heavily stained areas (persistent areas), rebound values ranged from 18 to 28 , while the values ranged from 25 to 32 for the transition zone and 28-45 for rock bridge area. For Block 2, rebound values ranged from 28 to 47 for the rock bridge area, but were much lower for persistent area (14-24). 

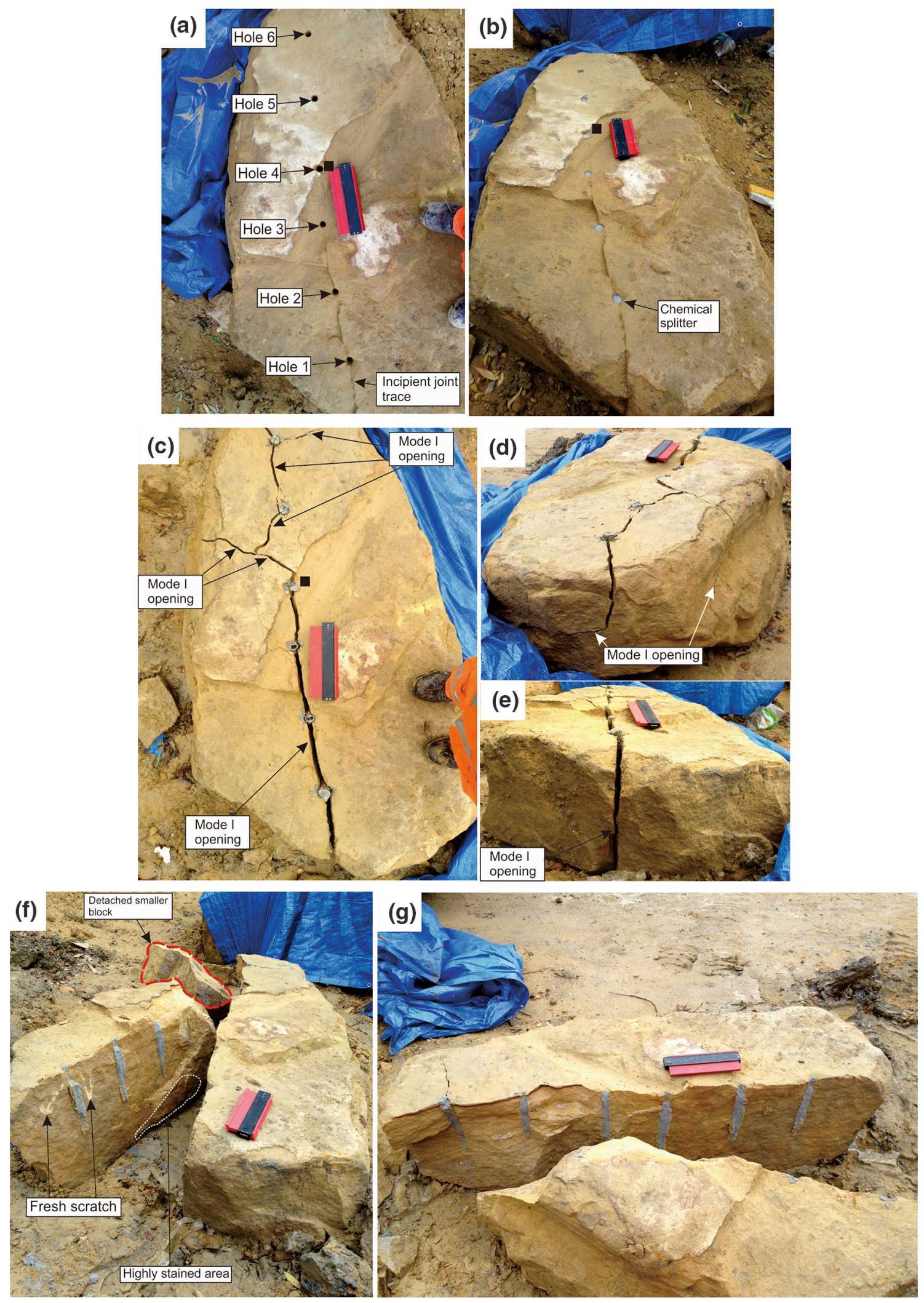

Fig. 10 Procedures and failure patterns of the FERM testing performed on Midgley Grit Sandstone Block 1 tested in Blackhill Quarry, West Yorkshire, UK. a Single joint trace terminating in rock and six holes drilled to split the block. b Chemical splitter injected into the pre-drilled holes. $\mathbf{c}-\mathbf{e}$ Failure patterns and fractures induced after $24 \mathrm{~h}$. f Two separated blocks and one smaller block. $\mathrm{g}$ The two larger separated blocks. Black rectangular dot shows the joint trace termination point. The profile meter for scale is $270 \mathrm{~mm}$ 

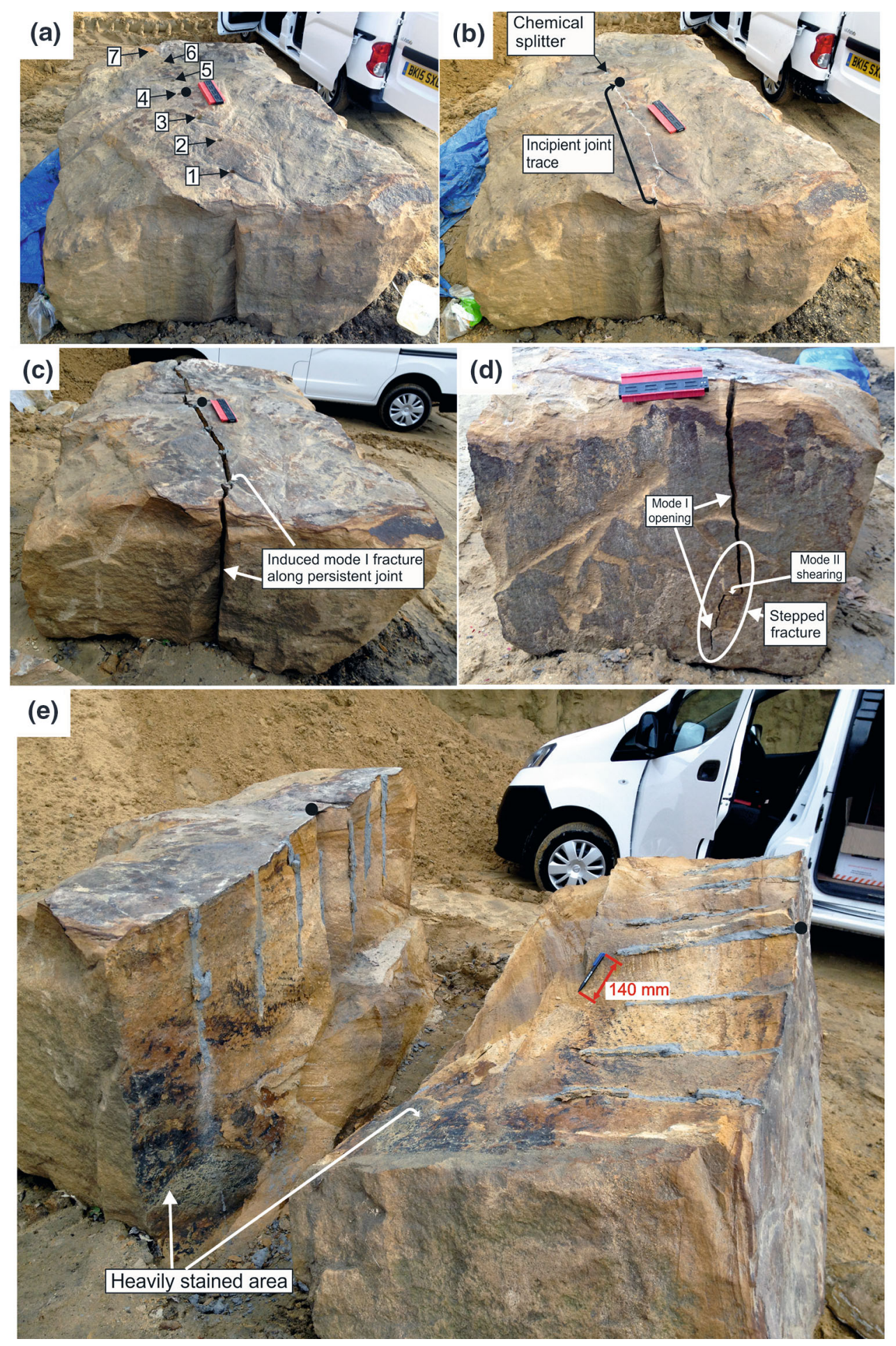

Fig. 11 a and b Procedures of forensic splitting of incipient rock discontinuity within Midgley Grit Sandstone Block 2 tested in Blackhill Quarry, West Yorkshire, UK. Failure patterns are shown in $\mathbf{c}$ and $\mathbf{d}$. The split parts are separated, and the exposed joint surfaces are shown in $\mathbf{e}$ 

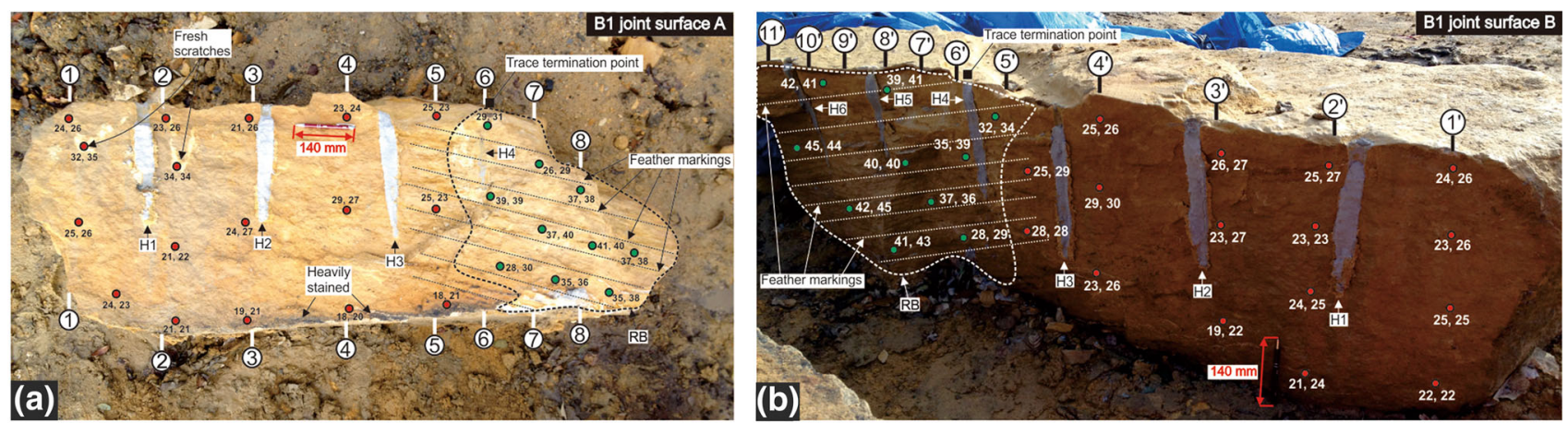

$\left(a_{1}\right)$

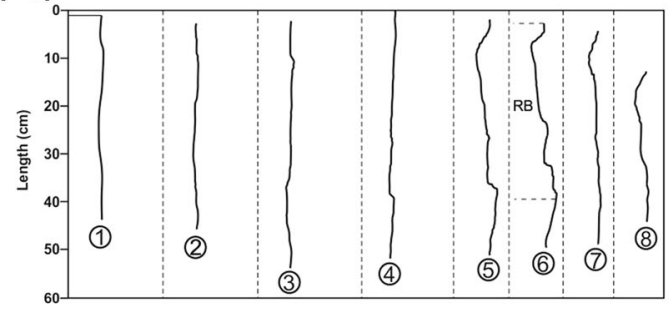

$\left(\mathbf{b}_{1}\right)$

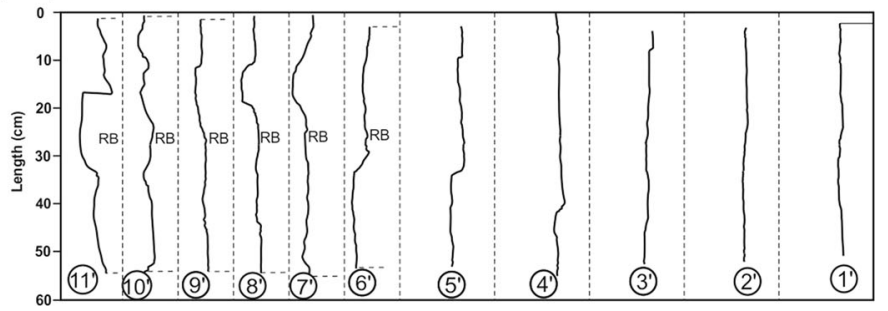

Fig. 12 a and b Opposite exposed incipient joint surfaces in Midgley Grit Sandstone Block 1 (i.e. B1 joint surface A and B1 joint surface B). $\mathbf{a}_{1}$ and $\mathbf{b}_{1}$ Roughness profiles of the two joint surfaces
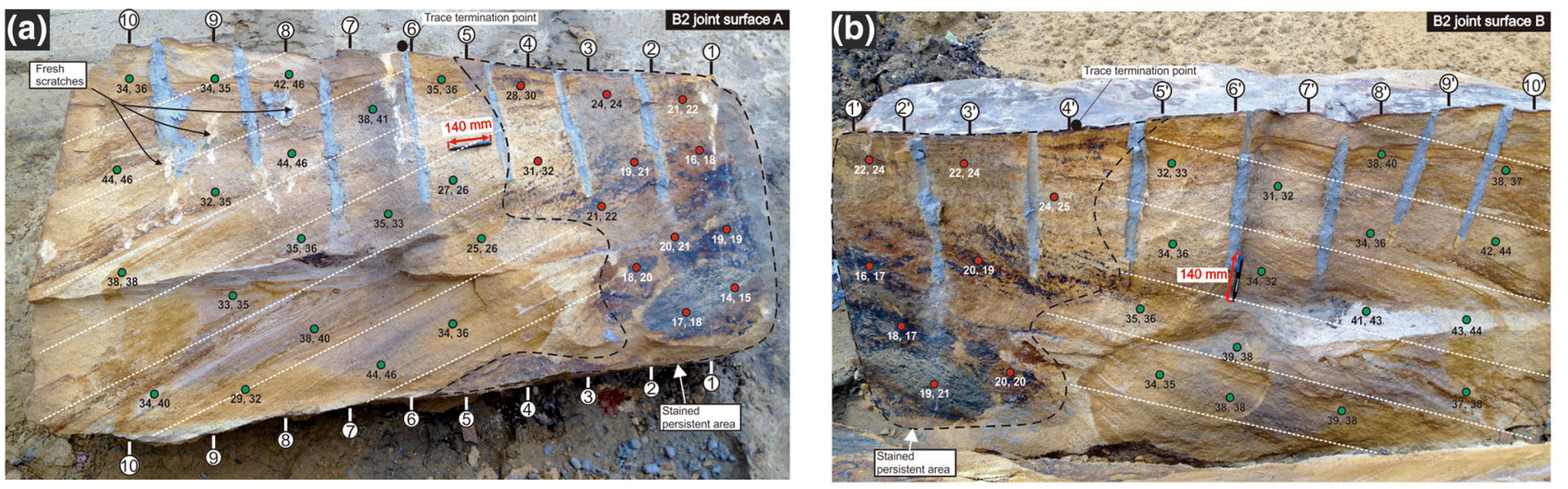

$\left(\mathbf{a}_{1}\right)$

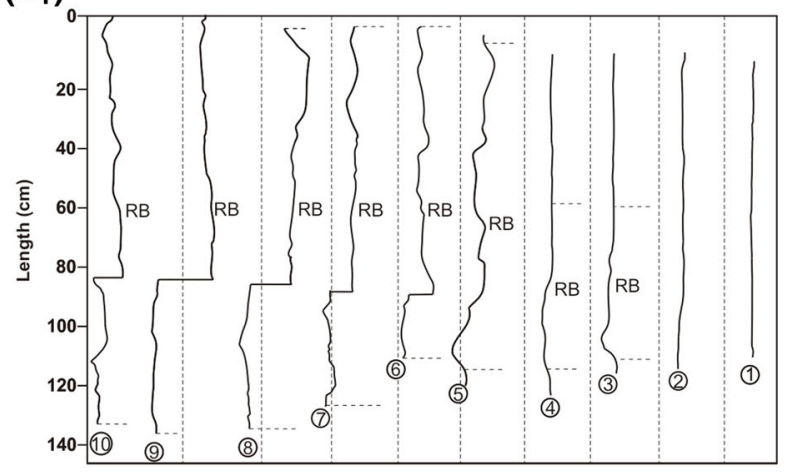

$\left(\mathbf{b}_{1}\right)$

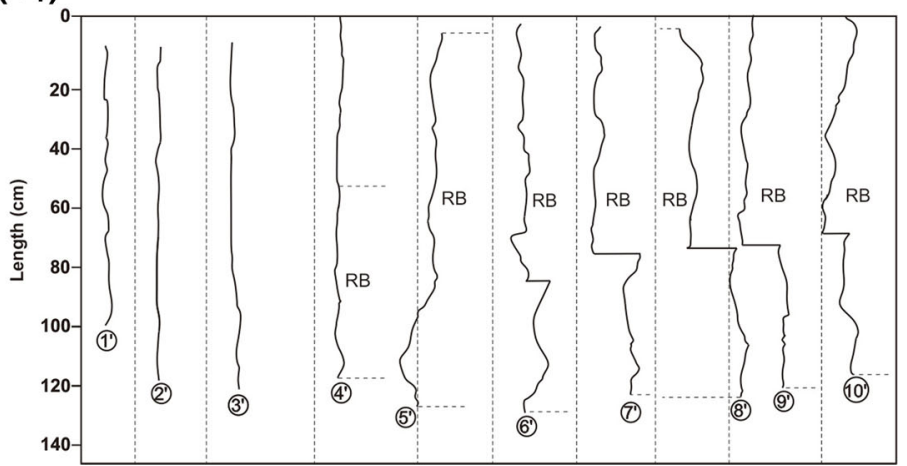

Fig. 13 a and b Opposite exposed incipient joint surfaces in Midgley Grit Sandstone Block 2 (i.e. B2 joint surface A and B2 joint surface B). $\mathbf{a}_{1}$ and $\mathbf{b}_{1}$ Roughness profiles of the two joint surfaces 

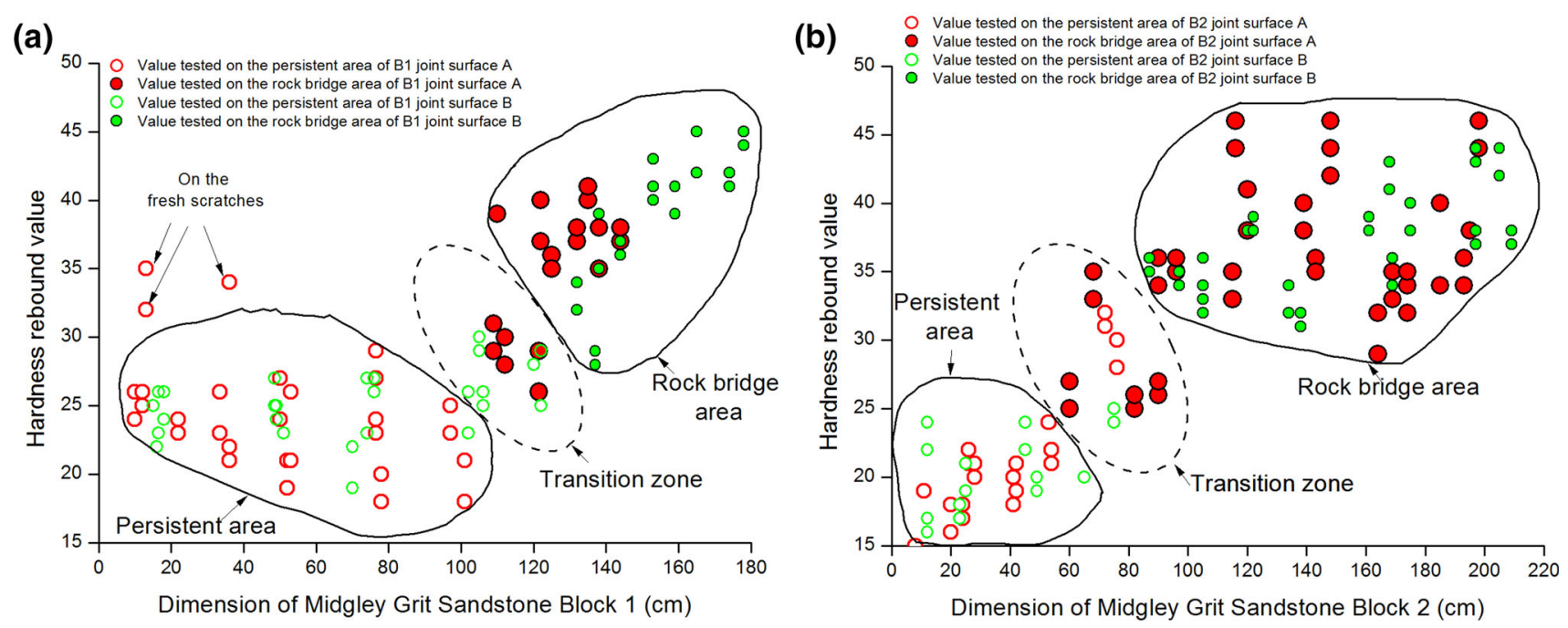

Fig. 14 Distribution of L-Schmidt hammer hardness rebound values of the exposed surfaces A and B of a Block 1 and $\mathbf{b}$ Block 2. (Please refer to the web version of this article for colour interpretation.) (colour figure online)

\section{Larger-Scale FERM Experiment at DRQ}

\subsection{Description of the Horton Formation Siltstone sample}

Figure 15a shows the tested rock block containing seven visible incipient discontinuity traces on the top surface. Relative orientations of these incipient discontinuity traces (considering only planar or near-planar traces including exposed free surfaces as representing discontinuities), are plotted in Fig. 15b assuming a north direction as shown in Fig. 15a, front view.

\subsection{Experimental Procedures and Dye Flow Along Discontinuities}

Five holes with depth of approximately $450 \mathrm{~mm}$ were drilled along the incipient rock joint trace (1), and fluorescein dye $\left(\mathrm{C}_{20} \mathrm{H}_{12} \mathrm{O}_{5}\right)$ was injected in an attempt to identify persistent portions (Fig. 16a). The block was then protected by a plastic cover and left for $24 \mathrm{~h}$ for the dye to penetrate by gravity. Chemical splitters were then injected as for the previous field experiments.

A fracture with an aperture of around $2 \mathrm{~mm}$ was induced after $24 \mathrm{~h}$ following the joint trace (1) which terminated at Hole 2 and then followed a zigzag pattern between Hole 2 and Hole 3 (Fig. 16b). Unexpectedly, it did not pass through Hole 3. A high tensile strength contribution (true cohesion) arising from rock bridges along this incipient rock joint was evident as the slab was not fully split, even though the fracture aperture at the top approached $50 \mathrm{~mm}$ (see Fig. 16c). The slab was eventually split using an excavator, and the exposed joint surfaces are presented in Fig. $17 \mathrm{a}$ and $\mathrm{b}$.

\subsection{Results and Observations}

Regarding the dye injection it was noted that seepage appeared from a section of one incipient joint trace on the front exposed surface (Fig. 16e) and from the incipient joint trace (1) on the left face of the block (Fig. 16d).

Figure 17 shows the exposed joint surfaces and roughness profiles. Fresh rock bridge areas were outlined by the dashed lines, and some traces of pre-existing joint planes (within the siltstone block) were revealed on exposed surfaces (black lines). Areal persistence of the incipient joint was about $62 \%$, compared to linear persistence of $32 \%$ from the joint trace (1) on the top surface. As for the Midgley Grit Sandstone, rock bridge areas were much rougher than persistent areas and showed hackle marks.

\section{Discussion}

Rock discontinuity persistence varies with geological settings, lithology and regional tectonic history (Tuckey and Stead 2016), and for a particular discontinuity, it will change with geological time (Hencher and Knipe 2007). Incipient discontinuities opened up as described in this paper using the FERM technique were observed to terminate within the rock matrix (for example, the joint trace shown in Fig. 11b). This tallies with the overall concept of discontinuity propagation attributed to the stress concentration and stress transferring (to the adjacent rock material) during the initial joint development (Mandl 2005; Hencher 2015). Two conditions are necessary for splitting along incipient discontinuities in rocks (Fairhurst 2004). Firstly, the true cohesive strength (essentially synonymous with tensile strength) is exceeded as the solid ruptures, and 
(a)
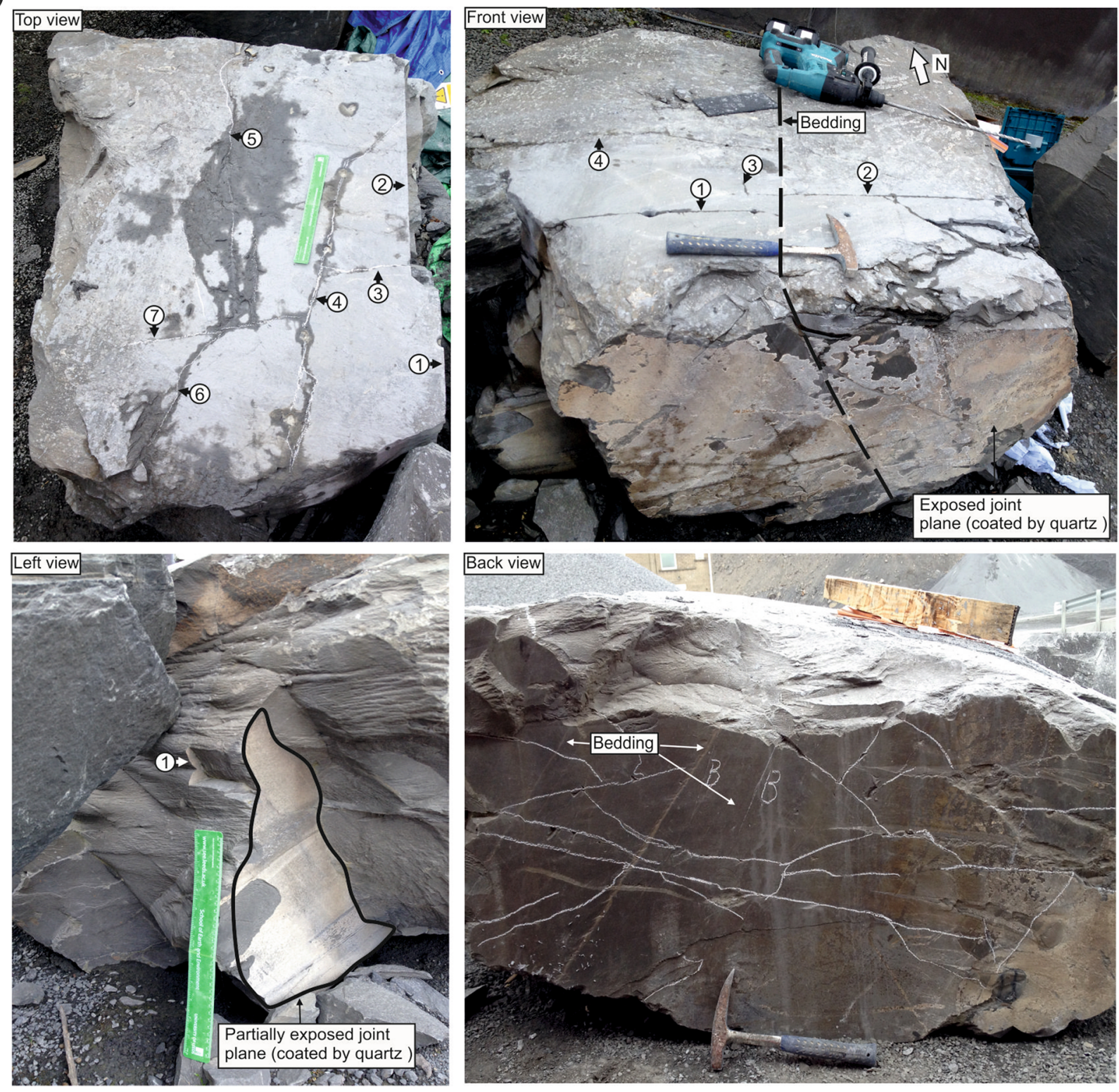

(b)

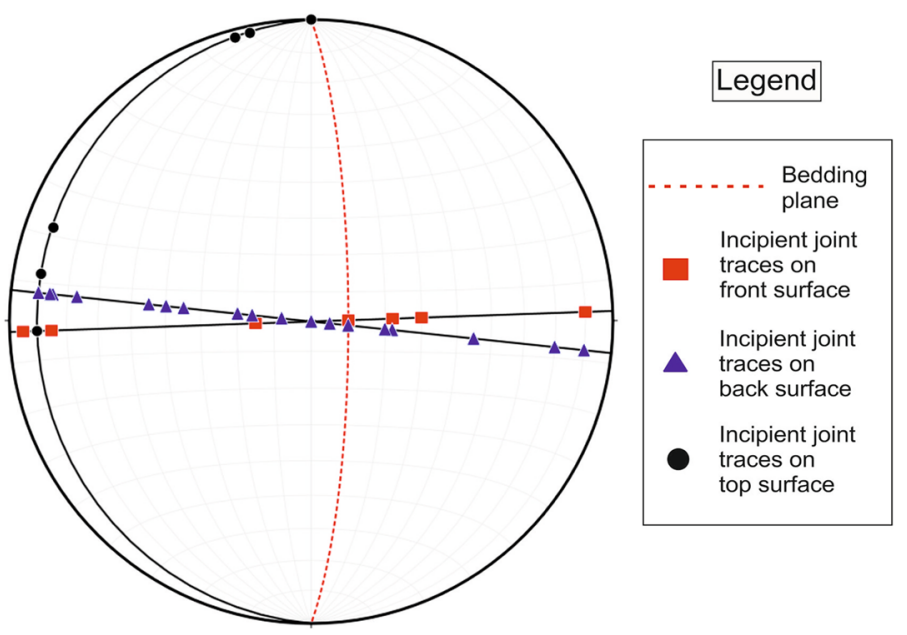


4Fig. 15 a Horton Formation Siltstone block tested at Dry Rigg Quarry, North Yorkshire, UK. The geological hammer for scale is $310 \mathrm{~mm}$. b Relative orientation of planar incipient discontinuity traces and exposed free surfaces on the Horton Formation Siltstone block in a. Note that discontinuity surfaces are plotted as plane and traces are plotted as poles

secondly, there must be adequate energy available to allow the continued development of two distinct joint surfaces and to allow the fracture to extend and propagate. This brittle fracturing process comprising fracture initiation and propagation is predominately controlled by the tensile strength of intact rock including its component grains (Hoek and Martin 2014).

Joint surface morphology is normally decorated by textures such as hackles and rib marks that reflect the joint initiation, orientation and propagation processes (Pollard and Aydin 1988; Ameen 1995). As evidenced from the field tests on both Midgley Grit Sandstone and Horton Formation Siltstone, splitting through rock bridges during FERM usually gave rise to clear hackle and rib marks (for example, in Figs. 13 and 17). The amplitude of surface
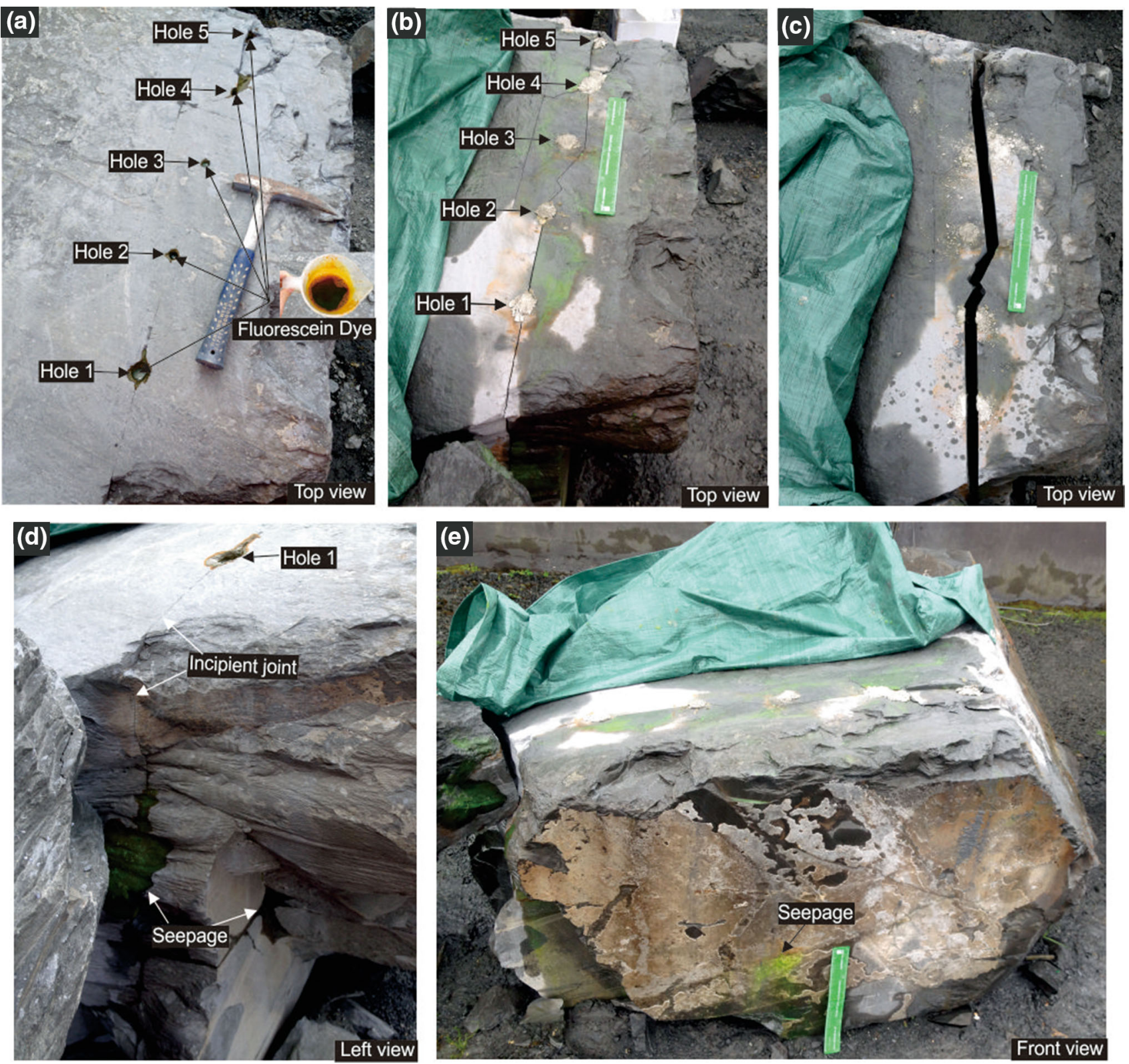

Fig. 16 FERM testing along incipient joint (1) from the Horton Formation Siltstone block. a Fluorescein dye $\left(\mathrm{C}_{20} \mathrm{H}_{12} \mathrm{O}_{5}\right)$ was poured into the pre-drilled holes prior to the forensic splitting. b Chemical splitter was injected and one fracture with an aperture of about $2 \mathrm{~mm}$ was induced after $24 \mathrm{~h}$. Block was still not fully split, even though the aperture on the top reached $>50 \mathrm{~mm}$ as shown in c. $\mathbf{d}$ and e Dye flowed out along persistent joint segments after $24 \mathrm{~h}$ before splitting. The geological hammer for scale is $310 \mathrm{~mm}$ 

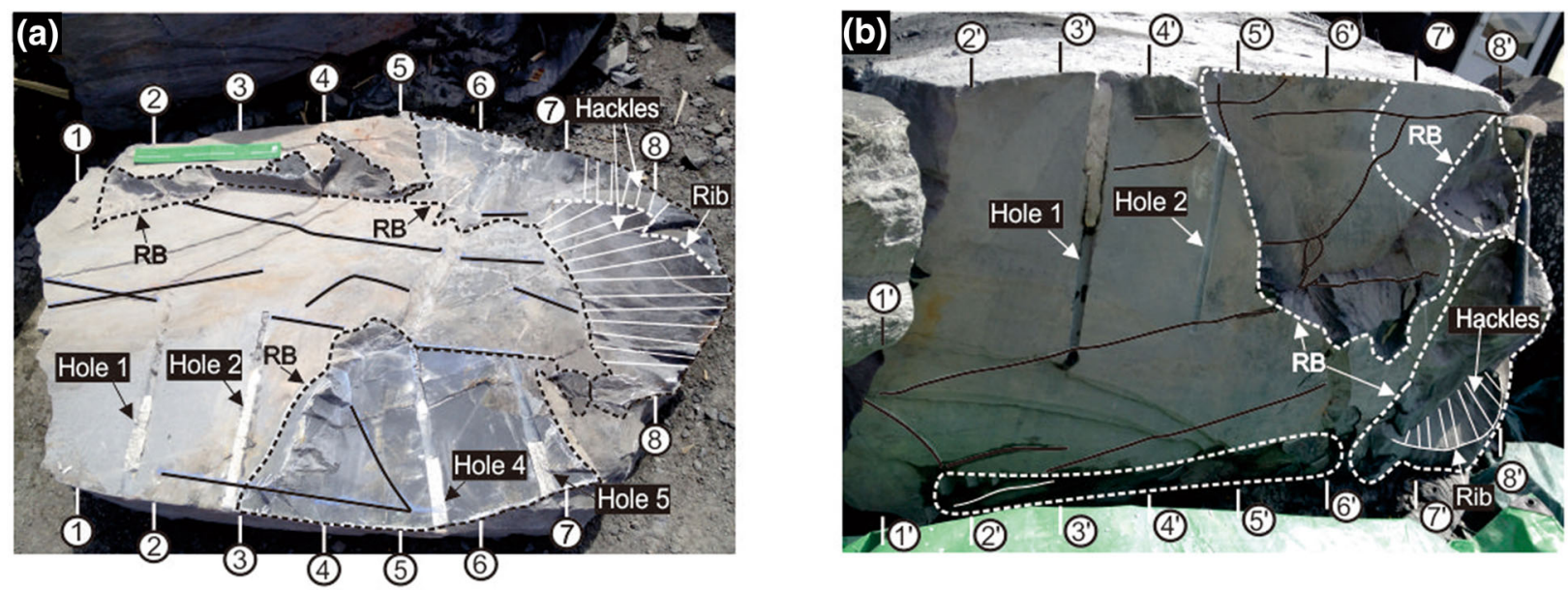

$\left(a_{1}\right)$

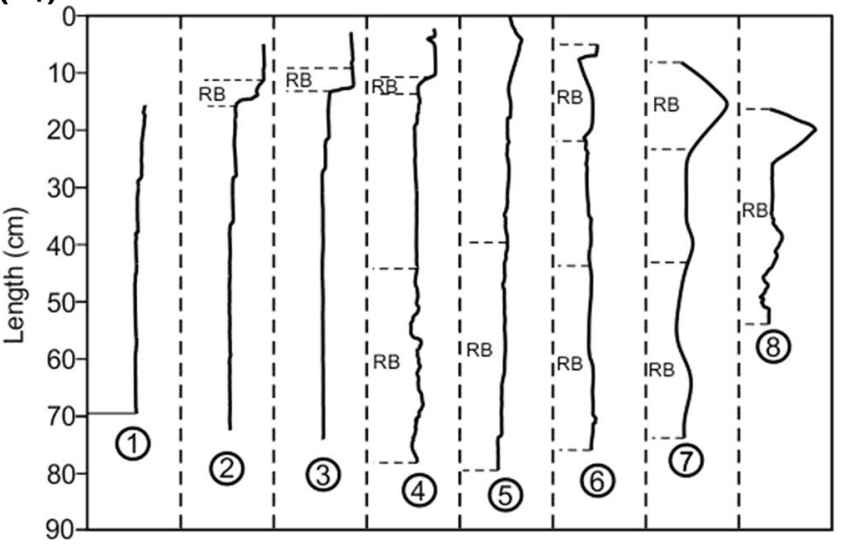

(b1)

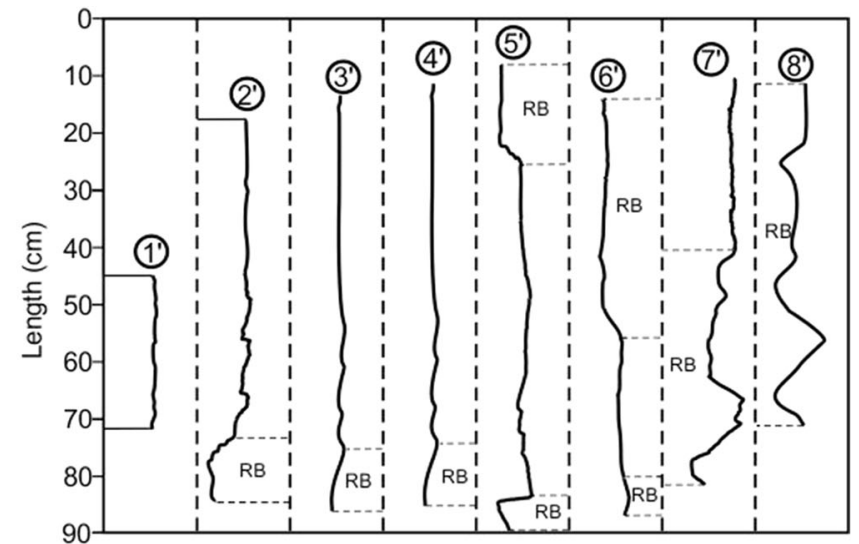

Fig. 17 a and $\mathbf{b}$ Opposite exposed incipient joint surfaces of Horton Formation Siltstone block. The geological hammer for scale is $310 \mathrm{~mm}$; $\mathbf{a}_{1}$ and $\mathbf{b}_{1}$ roughness profiles of the two joint surfaces. The rule for scale is $314 \mathrm{~mm}$

roughness in the rock ridge areas was much larger than that in the areas that were already well defined as essentially persistent (albeit incipient). This difference might be attributed to the different mechanisms, stress states and rate of growth of discontinuities formed naturally compared to those created by FERM, essentially instantaneously and without broad and remote stress confinement. For natural joints, stresses around joint tips control the joint propagation path under loading. Once fracture naturally initiates, it tends to propagate in a plane provided the broad, mass principal stresses remain consistent along the extension of joint plane (Pollard and Aydin 1988). For the fractures induced during FERM, stress concentration around the chemical splitter-filled holes (Shang 2016) leads to a progressive fracturing under localised stress conditions that are quite different to the conditions under natural joint formation. The inhomogeneity of rock material surely also contributes to the variation of surface roughness. At a microscale, rocks comprise an assemblage of minerals, with individual grains variably orientated and of varying sizes with pores between grains (Fairhurst 2004). Tensile fracture induced during FERM may transverse rock bridge areas along a very irregular path, thus leading to a rough surface. Whatever the reason, the clear difference in surface roughness (in this set of experiments) can be utilised as a guideline to distinguish pre-existing rock bridge areas from pre-existing persistent areas of incipient discontinuity.

As for Midgley Grit Sandstone tested, both in the laboratory (Fig. 9) and in the field (Fig. 13), the weathering process has left a clear morphological signature with brown and black staining on pre-existing persistent areas. Iron oxides (haematite) and biotite appeared in the brown and black weathered areas (Shang et al. 2016). In comparison, weathering did not penetrate deeply into the Horton Formation Siltstone (for the samples tested).

As seen from the exposed joint surfaces (for example, Fig. 17), rock bridges can exist with very irregular geometries in an incipient discontinuity plane. 


\section{Conclusions}

A new technique 'forensic excavation of rock masses (FERM)' has been developed to investigate discontinuity areal persistence. Laboratory- and field-based FERM experiments on two lithologies were performed as application examples. Conclusions drawn from this study are as follows:

1. FERM can be used in the investigation of areal extent (persistence) of planar discontinuities.

2. In some lithologies such as the Midgley Grit in this study, pre-existing (here called persistent) sections of incipient joint surfaces can be distinguished from rock bridges by staining (weathering), compared to intact rock bridges broken during FERM which show the fresh rock colour.

3. In both lithologies tested here, amplitude of surface roughness of a discontinuity surface, created by breakage of rock bridges during FERM, was generally greater than that along pre-existing (here called persistent) sections of incipient joint planes. Breakage of rock bridges during FERM also produced clearly recognisable marks such as fresh feather or hackle marks.

4. Schmidt hammer rebound values of persistent stained areas were generally smaller than those of nonpersistent rock bridge areas.

5. Using a combination of (2)-(4) above, it was possible to distinguish pre-existing (persistent) sections from intact rock bridges on the exposed surfaces of incipient discontinuities after FERM, for both lithologies. Both laboratory and field FERM experiments described in this paper demonstrate that trace length is a poor predictor of the areal persistence.

One of the outcomes of this work is to demonstrate through experiment the potential errors in attempting to characterise true persistence of discontinuities by measurement of visible trace length (a traditional way). This has obvious consequences for the way that rock masses are characterised and modelled. FERM allows measurement of real persistence as a way of improving our knowledge of fundamental rock mass qualities. Clearly, FERM cannot be used routinely in ground investigation but, it is considered, does have a real role in fundamental research studies of rock masses that will hopefully allow better characterisation in the future.

In the authors' view, the method may well be applicable at larger scale (see, for example, Fig. 3). There are no insurmountable safety or access problems-it just needs proper planning and control.
It is envisaged, for example, that forensic excavation of disused quarries might be used to investigate all sorts of important parameters including connectivity and channel flow and how these can be correlated with the geological history at the site. This would advance the knowledge of specific rock masses and locations, perhaps to be used for better characterisation of potential nuclear waste repositories where, at present, characterising the mass from boreholes and geophysics leaves many gaps in understanding.

The method would also be applicable to generic investigation of how weathering at a mass scale affects persistence-the authors see many potential applicationsleading potentially to much better refined rock mass classifications than RMR, Q or GSI. The technique has been shown to be useful at laboratory scale and field scale over the range of a few metres, but this is just 'scratching the surface' of the application of the technique both for research and for site-specific characterisation.

Acknowledgements The practical and enthusiastic support of managers Michael Cardus of Dry Rigg Quarry and Craig Morrell of Blackhill Quarry and their quarry staff is gratefully acknowledged.

Open Access This article is distributed under the terms of the Creative Commons Attribution 4.0 International License (http://crea tivecommons.org/licenses/by/4.0/), which permits unrestricted use, distribution, and reproduction in any medium, provided you give appropriate credit to the original author(s) and the source, provide a link to the Creative Commons license, and indicate if changes were made.

\section{References}

Abellan A, Vilaplana J, Martinez J (2006) Application of a long range terrestrial laser scanner to a detailed rockfall study at Vall de Nuria (Eastern Pyrenees, Span). Eng Geol 88:136-148

Alzo'ubi A, Martin CD, Crude DM (2007) A discrete element damage model for rock slopes. In: 1st Canada-US rock mechanics symposium, Vancouver, Canada, pp 503-510

Ameen MS (1995) Fractography: fracture topography as a tool in fracture mechanics and stress analysis. An introduction. Geol Soc Lond Spec Publ 92:1-10

Aydin A (2014) ISRM suggested method for determination of the Schmidt Hammer Rebound Hardness: revised version. The ISRM suggested methods for rock characterization, testing and monitoring: 2007-2014. Springer, Berlin, pp 25-33

Barton N, Choubey V (1977) The shear strength of rock joints in theory and practice. Rock Mech Rock Eng 10(1):1-54

Bonilla-Sierra V, Scholtès L, Donzé FV, Elmouttie M (2015) DEM analysis of rock bridges and the contribution to rock slope stability in the case of translational sliding failures. Int J Rock Mech Min Sci 80:67-78

Einstein HH, Baecher GB (1983) Probabilistic and statistical methods in engineering geology, specific methods and examples Part I: exploration. Rock Mech Rock Eng 16:39-72

Einstein HH, Veneziano D, Baecher GB, Oreilly KJ (1983) The effect of discontinuity persistence on rock slope stability. Int J Rock Mech Min Sci 20(5):227-236 
Fairhurst C (2004) Fundamental considerations relating to the strength of rock. In: Report on the workshop on extreme ground motions at Yucca Mountain, US Geological Survey, Menlo Park, California, pp 1-41

Ferrero AM, Forlani G, Roncella R, Voyat HI (2009) Advanced geostructural survey methods applied to rock mass characterization. Rock Mech Rock Eng 42(4):631-665

Fu W, Ames BC, Bunger AP, Savitski AA (2016) Impact of partially cemented and non-persistent natural fractures on hydraulic fracture propagation. Rock Meck Rock Eng 49(11):4519-4526

Gani MSJ (1997) Cement and concrete. Chapman and Hall, London, p 205

Han XD, Chen JP, Wang Q, Li YY, Zhang W, Yu TW (2015) A 3D fracture network model for the undisturbed rock mass at the Songta dam site based on small samples. Rock Mech Rock Eng 49(2):611-619

Harrison JP, Reid TR (2010) A semi-automated methodology for discontinuity trace detection in digital images of rock mass exposures. Int J Rock Mech Min Sci 37:1073-1089

Hencher SR (2006) Weathering and erosion processes in rockimplications for geotechnical engineering. Invited paper. In: Proceedings symposium on Hong Kong soils and rocks, March 2004, Institution of Mining, Metallurgy and Materials and Geological Society of London, pp 29-79

Hencher SR (2014) Characterizing discontinuities in naturally fractured outcrop analogues and rock core: the need to consider fracture development over geological time. Geol Soc Lond Spec Publ Adv Study Fract Reserv 374:113-123

Hencher SR (2015) Practical rock mechanics. Spon Press, Taylor and Francis Group, London, p 356

Hencher SR, Knipe R (2007) Development of rock joints with time and consequences for engineering. In: Proceeding of the 11th congress of the international society for rock mechanics, Lisbon, Portugal, pp 223-226

Hoek E, Martin CD (2014) Fracture initiation and propagation in intact rock-a review. J Rock Mech Geotech 6:287-300

Huynh MP, Laefer DF (2009) Expansive cements and soundless chemical demolition agents: state of technology review. In: 11th conference on science and technology, Ho Chi Minh City, Vietnam

ISRM (1978) Suggested methods for quantitative description of discontinuities in rock masses. Int $\mathrm{J}$ Rock Mech Min Sci Geomech Abstr 15:319-368

Jiang MJ, Jiang T, Crosta GB, Shi ZM, Chen H, Zhang N (2015) Modelling failure of jointed rock slope with two main joint sets using a novel DEM bond contact model. Eng Geol 193:79-96

Kemeny J (2005) Time-dependent drift degradation due to the progressive failure of rock bridges along discontinuities. Int $\mathbf{J}$ Rock Mech Min Sci 42:35-46

Kim BH, Cai M, Kaiser PK, Yang HS (2007) Estimation of block sizes for rock masses with non-persistent joints. Rock Mech Rock Eng 40(2):169-192

Mandl G (2005) Rock joints. The mechanical genesis. Springer, Oxford, p 211p
Medici G, West LJ, Mountney NP (2016) Characterizing flow pathways in a sandstone aquifer: tectonic vs sedimentary heterogeneities. J Contam Hydrol 194:36-58

Natanzi AS, Laefer DF (2014) Using chemicals ad demolition agents near historic structures. In: 9th International conference on structural analysis of historical constructions, Mexico City, Mexico

Norbury D (2010) Soil and rock description in engineering practice. CRC Press, Boca Raton, p 288p

O'Reilly KJ (1980) The effect of joint plane persistence on rock slope reliability. PhD thesis, Massachusetts Institute of Technology, USA, p 553

Palmstrőm A (2005) Measurements of and correlations between block size and rock quality designation (RQD). Tunn Undergr Space Technol 20(4):362-377

Park HJ (2005) A new approach for persistence in probabilistic rock slope stability analysis. Geosci J 9(3):287-293

Pells PJ, Bieniawski ZT, Hencher SR, Pells SE (2017) RQD: time to rest in peace. Can Geotech J. doi:10.1139/cgj-2016-0012

Pollard DD, Aydin A (1988) Progress in understanding jointing over the past century. Geol Soc Am Bull 100:1181-1204

Priest SD, Hudson JA (1981) Estimation of discontinuity spacing and trace length using scanline surveys. Int J Rock Mech Min Sci Geomech Abstr 18:183-197

Rawnsley KD (1990) The influence of joint origin on engineering properties. PhD thesis, the University of Leeds. Leeds, United Kingdom, p 388

Shang J (2016) Persistence and tensile strength of incipient rock discontinuities. $\mathrm{PhD}$ thesis, the University of Leeds. Leeds, United Kingdom, p 248

Shang J, Hencher SR, West LJ (2015) Tensile strength of incipient discontinuities. In: Proceedings of the ISRM regional symposium Eurock 2015 \& 64th Geomechanics Colloquium, Salzburg, Austria, pp 565-570

Shang J, Hencher SR, West LJ (2016) Tensile strength of geological discontinuities including bedding, rock joints and mineral veins. Rock Mech Rock Eng 49(11):4213-4225

Smedley PL, Neumann I, Brown S (2005) The Permo-Triassic sandstone aquifer of shropshire. Baseline Report Series:20, British Geology Survey

Sturzenegger M, Stead D (2009) Quantifying discontinuity orientation and persistence on high mountain rock slopes and large landslides using terrestrial remote sensing techniques. Nat Hazards Earth Syst Sci 9:267-287

Tuckey Z, Stead D (2016) Improvements to field and remote sensing methods for mapping discontinuity persistence and intact rock bridges in rock slopes. Eng Geol 208:136-153

Umili G, Ferrero A, Einstein HH (2013) A new method for automatic discontinuity traces sampling on rock mass $3 \mathrm{D}$ model. Comput Geosci 51:182-192

Wasantha PLP, Ranjith PG, Haque A, Kodikara J, Bouazza A (2011) Implications of joint properties on the strength of jointed rock mass. In: GeoHunan International Conference: advances in Unsaturated Soil, Geo- Hazard, and Geo-Environmental Engineering, Hunan, China, pp 258-266 